\title{
Detecção de infiltração em áreas internas de edificações com termografia infravermelha: estudo de caso
}

\author{
Infiltration detection in internal areas of buildings using \\ infrared thermography: case study
}

\begin{tabular}{|c|c|}
\hline & $\begin{array}{l}\text { Joaquin Humberto Aquino Rocha } \\
\text { Cynthia Firmino dos Santos } \\
\text { Jaquelline Barros de Oliveira } \\
\text { Larissa Kelly dos Santos Albuquerque } \\
\text { Yêda Vieira Póvoas }\end{array}$ \\
\hline & $\begin{array}{l}\text { Resumo } \\
\text { termografia infravermelha é uma técnica de inspeção não destrutiva } \\
\text { com uso crescente em obras civis. Sua aplicação específica na } \\
\text { detecção de infiltração ainda está em desenvolvimento. O objetivo } \\
\text { principal do trabalho é verificar a aplicabilidade da termografia }\end{array}$ \\
\hline $\begin{array}{r}\text { 1Joaquin Humberto Aquino } \\
\text { Rocha } \\
\text { 'Escola Politécnica de Pernambuco } \\
\text { Recife - PE - Brasil }\end{array}$ & $\begin{array}{l}\text { Palavras-chave: Termografia infravermelha. Infiltração. Umidade. Manifestações } \\
\text { patológicas. } \\
\text { Abstract }\end{array}$ \\
\hline $\begin{array}{r}\text { 3aquelline Barros de Oliveira } \\
{ }^{3} \text { Escola Politécnica de Pernambuco } \\
\text { Recife - PE - Brasil }\end{array}$ & $\begin{array}{l}\text { Infrared thermography is a non-destructive inspection technique with increasing } \\
\text { use in construction works. Its specific application in detecting infiltrations is still in } \\
\text { development. The main objective of this study is to verify the applicability of } \\
\text { infrared thermography in the detection of humidity in internal areas that present } \\
\text { this pathological manifestation or minimal signs related to this problem. Internal } \\
\text { inspections were carried out in case studies located in areas vulnerable areas to } \\
\text { infiltration. The study was conducted passively during the rainy season. The }\end{array}$ \\
\hline $\begin{array}{r}{ }^{4} \text { Larissa Kelly dos Santos } \\
\text { Albuquerque } \\
{ }^{4} \text { Escola Politécnica de Pernambuco } \\
\text { Recife - PE - Brasil }\end{array}$ & $\begin{array}{l}\text { results show that detection is possible during the day, without difficulties, where } \\
\text { the areas affected by the infiltration present lower temperatures than the areas } \\
\text { without humidity. The researchers observed that the larger the temperature } \\
\text { difference, the greater the clarity of the thermal imaging. However, the coating of } \\
\text { the inspected surfaces may interrupt the formation of the thermal contrasts, }\end{array}$ \\
\hline $\begin{array}{r}{ }^{5} \text { Yêda Vieira Póvoas } \\
{ }^{5} \text { Escola Politécnica de Pernambuco } \\
\text { Recife - PE - Brasil }\end{array}$ & $\begin{array}{l}\text { reducing the quality of the results. Infrared thermography is a useful tool for } \\
\text { detecting non-visible or early-stage infiltrations because it provides location and } \\
\text { affected area information, but certain factors must be considered for effective } \\
\text { inspection as the external environmental conditions of the study site, camera }\end{array}$ \\
\hline & specifications and infiltration characteristics. \\
\hline & Keywords: Infrared thermography. Infiltration. Moisture. Pathology. \\
\hline
\end{tabular}

ROCHA, J. H. A.; SANTOS, C. F. dos; OLIVEIRA, J. B. de; ALBUQUERQUE, L. K. dos S.; PÓVOAS, Y. V. Detecção de infiltração em áreas internas de edificações com termografia infravermelha: estudo de caso. Ambiente Construído, Porto Alegre, v. 18, n. 4, p. 329-340, out./dez. 2018. 


\section{Introdução}

A ação da água tem um efeito significativo e negativo com respeito à durabilidade das edificações, pois pode causar danos ou desencadear grande parte das manifestações patológicas tradicionais existentes. Defeitos relacionados à infiltração de água nas edificações podem causar problemas como transtornos na relação entre construtor e usuário final e elevação dos custos para as correções das falhas (BERNHOEFT; MELHADO, 2009). Tanto a presença de umidade quanto as mudanças em seu estado físico podem causar condições insalubres para os usuários, resultantes do crescimento biológico e da degradação de materiais e componentes de construção. Para um correto diagnóstico é importante definir o tipo de umidade, que pode ser: de construção, ascensional, de precipitação, de condensação, devido a fenômenos de higroscopicidade e devido a causas fortuitas (BARREIRA; ALMEIDA; DELGADO， 2016; OLIVEIRA, 2013).

A umidade representa um problema de difícil solução e de grande frequência nas edificações. Fatores como idade da edificação, clima, materiais, práticas construtivas utilizadas e grau de controle de qualidade durante sua execução influenciam o quanto esse tipo de anomalia ocorre. A umidade pode se manifestar de várias formas, como manchas, mofo ou bolor, fissuras, entre outros (JONOV; NASCIMENTO; PAULA E SILVA, 2013). Muitas vezes a impermeabilização é indicada como principal contribuinte para as anomalias nas edificações relacionadas à umidade, que tem por função preservar a estrutura por meio do entendimento das forças naturais e seus efeitos durante o ciclo de vida; no entanto, as falhas no projeto de impermeabilização e até mesmo uma manutenção inadequada podem produzir esses problemas (RIGHI, 2009; OTHMAN et al., 2015).

Normalmente a avaliação dos problemas relacionados à umidade e de seu teor é realizada por métodos destrutivos; no entanto, na área de diagnóstico de manifestações patológicas é priorizada a utilização de ferramentas não destrutivas devido ao inconveniente causado por técnicas destrutivas, principalmente nas construções habitadas (FREITAS; CARASEK; CASCUDO, 2014). A termografia infravermelha é um ensaio não destrutivo usado com esse propósito, pois não precisa contato direto com a estrutura, pode analisar áreas, e os resultados são em tempo real (AGGELIS et al., 2010; OH et al., 2013; BAGAVATHIAPPAN et al., 2013), além de haver minimização de riscos e de interferências na vida dos usuários (BARREIRA; FREITAS, 2007).
O ensaio utiliza como princípio básico que todos os objetos com temperatura acima do zero absoluto $(0 \mathrm{~K})$ emitem radiação na faixa infravermelha do espectro eletromagnético. A radiação detectada de uma maneira sem contato através de uma câmera termográfica é transformada em sinais elétricos para depois originar uma imagem térmica, conhecida também como termograma, em que cada cor representa um intervalo de temperatura (BAGGATHIAPPAN et al., 2013; SILVA, 2012; GUCUNSKI et al., 2013). O ensaio pode ser realizado passivamente, capturando a temperatura natural do elemento causada pelo ambiente $(\mathrm{OH}$ et al., 2013); outra forma é ativa, fornecendo calor para aquecer o objeto e revelar defeitos, denominada termografia ativa (REHMAN et al. 2016).

Os mecanismos de transferência de calor são a radiação, a condução e a convecção, os quais afetam o fluxo de calor através do material. Embora a radiação seja o parâmetro medido pela câmera termográfica, a condutividade térmica dentro do material e a convecção de calor em torno do objeto têm influência nos resultados (JIMENO, 2011).

$\mathrm{O}$ ensaio tem seu uso consolidado na engenharia elétrica (LIZAK; KOLCUN, 2008; HUDA; TAIB, 2013) e mecânica (KUTIN; ADAMOVIE, 2010; ZHAO et al., 2017), como em outras áreas (BAGAVATHIAPPAN et al., 2013); no entanto, o ensaio é relativamente novo na construção civil, especificamente na inspeção de obras civis (REHMAN et al., 2016; FOX; GOODHEW; WILDE, 2016; O'GRADY; LECHOWSKA; HARTE, 2017), e sua aplicação específica na detecção de umidade é cada vez mais desenvolvida (BARREIRA; ALMEIDA; DELGADO, 2016; OLIVEIRA, 2013; LERMA; CABRELLES; PORTALÉS, 2011; MELRINHO; MATIAS; FARIA, 2015; BARREIRA; ALMEIDA; MOREIRA, 2017; EDIS; FLORES-COLEN; BRITO, 2014)

Apesar do avanço nas aplicações da termografia infravermelha na detecção de manifestações patológicas ocultas, a detecção de umidade ainda pode ser um problema, pois muitas vezes a detecção é feita em áreas onde existem marcas visíveis, quando a degradação do material é avançada, o que mostra um cenário não desejado; portanto, é importante identificar os focos de propagação que estejam em fase embrionária e prevenir futuras infiltrações para evitar reparos custosos. O objetivo do presente trabalho é avaliar a potencialidade do ensaio da termografia infravermelha na detecção de umidade em áreas

330 Rocha, J. H. A.; Santos, C. F. dos; Oliveira, J. B. de; Albuquerque, L. K. dos S.; Póvoas, Y. V. 
internas localizadas em áreas vulneráveis à infiltração, como em ambientes degradados.

\section{Método}

Para verificar a utilização da termografia infravermelha na detecção de umidade foram realizadas inspeções em ambientes internos por meio de estudos de caso. Os ambientes escolhidos para a execução do ensaio de termografia infravermelha foram as salas do Laboratório de Informática e Eletrônica (LIE) e do Laboratório Avançado de Construção Civil (LACC), localizadas na Escola Politécnica da Universidade de Pernambuco. Os locais do estudo são mostrados na Figura 1. Foram analisadas cinco paredes, quatro no LIE e uma no LACC, além do teto dos ambientes.

O parâmetro de escolha das salas para a realização do ensaio foi a procura de ambientes que, com uma inspeção visual, permitissem detectar algumas evidências mínimas da possível presença de infiltração, como também áreas que não apresentassem problemas visíveis, mas cuja localização tivesse tendência a desenvolver infiltrações.

O estudo foi realizado durante o período de chuvas para observar a infiltração causada por esse fenômeno. Foram realizadas imagens termográficas das áreas internas e as imagens digitais da laje, no caso do LIE, e da parede externa, no caso do LACC.

A forma de aplicação da termografia foi passiva, uma vez que as áreas analisadas foram internas, sem a presença de fontes externas de calor, como também sem a presença solar direta. Por se tratar de ambiente interno, a condição ambiental externa não tem influência direta nos resultados.

O equipamento utilizado foi a câmera termográfica FLIR T460, cujas principais características estão apresentadas na Tabela 1 .

Figura 1 - Locais do ensaio de termografia infravermelha: (a) localização; (b) esquema do LIE; e (c) esquema do LACC
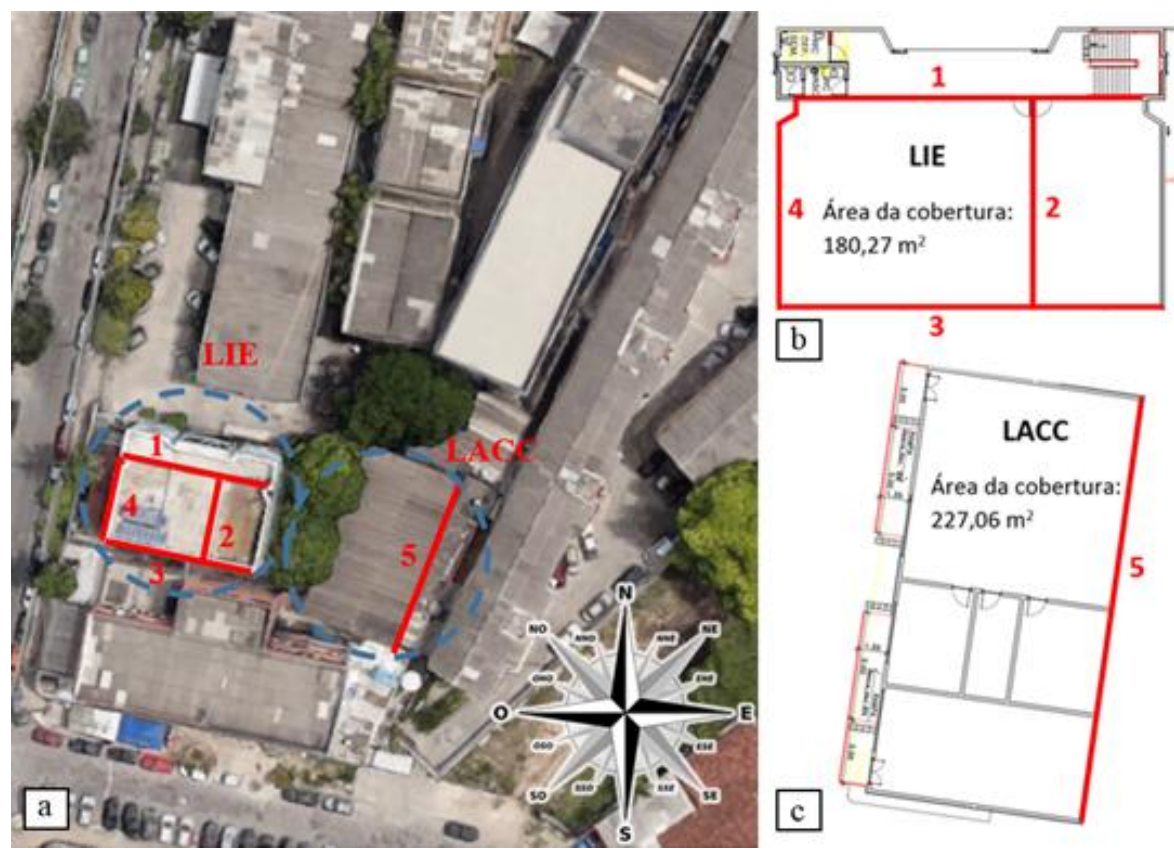

Fonte: adaptado de Google (2017).

Tabela 1 - Características da câmera termográfica

\begin{tabular}{l|c}
\hline \multicolumn{1}{c|}{ Modelo } & FLIR T460 \\
\hline Escala de temperatura & $-20{ }^{\circ} \mathrm{C} \mathrm{a} 1.200^{\circ} \mathrm{C}$ \\
Resolução IR & $320 \times 240$ pixels \\
Sensibilidade térmica & $<0,045^{\circ} \mathrm{C}$ \\
Precisão & $\pm 2{ }^{\circ} \mathrm{C}$ ou $2 \%$ de leitura \\
Câmera digital & $3,1 \mathrm{MP}$ \\
Peso & $0,880 \mathrm{~kg}$ \\
\hline
\end{tabular}

Fonte: FLIR (2014). 
Durante o tempo do ensaio, a distância da câmera ao objeto foi variada entre $2 \mathrm{~m}$ e $3 \mathrm{~m}$, como também o foco da câmera, visando ter boa resolução dos termogramas e melhores resultados. Embora a norma NBR 15572 (ABNT, 2013) recomende evitar inspeções com velocidade de vento acima de $20 \mathrm{~km} / \mathrm{h}$ e umidade relativa do ar acima de $90 \%$, neste caso, por serem áreas internas, essas recomendações não foram atendidas. Não obstante, durante o ensaio a umidade relativa do ar interior foi em torno de $40 \%$, valor baixo devido ao ar condicionado.

O método para determinar a emissividade das paredes foi o da "fita preta", em que foi utilizada uma fita com emissividade conhecida para determinar a emissividade das paredes estudadas. Um pedaço da fita foi colocado nas paredes para depois conseguir o valor da emissividade, o qual é obtido através de interações até que a temperatura da parede seja igual à temperatura da fita, que corresponde à emissividade do material. $\mathrm{O}$ valor obtido em todos os casos foi 0,94 . Para a obtenção do parâmetro da temperatura refletida usou-se o método de reflexão descrito no manual da câmera (FLIR, 2014), que consiste em medir a temperatura de um pedaço de alumínio dobrado e amassado, para o qual é usado o valor de emissividade de 1 , sendo esse parâmetro determinado para cada termograma.

\section{Análise e discussão dos resultados}

\section{Laboratório de Informática e Eletrônica (LIE)}

Na Figura 2 observa-se a laje do edifício, que é descoberta, e nota-se a presença de água em sua superfície após a ocorrência de chuva. A impermeabilização dessa laje apresentou-se desgastada durante a inspeção visual. Não obstante, no dia da execução do ensaio, a laje do edifício estava passando por serviços de manutenção a fim de reduzir as infiltrações de água, que estavam afetando a edificação.

Neste setor foram analisadas quatro paredes e o teto das salas. A parede 1, localizada na orientação norte (Figura 1), apresentava revestimento de pintura e, como se trata de parede interna, não houve incidência solar direta durante o dia. Embora exista uma janela em frente a ela, durante o dia e no momento do ensaio, realizado às $16 \mathrm{~h}$, a radiação solar não atingiu a parede do estudo.

Podia-se observar a presença de infiltração no teto, pois existia a presença de bolor, grandes manchas, uma leve fissura e ainda descolamentos, mas a parede não apresentava manchas ou indícios de umidade (Figura 3a). A imagem térmica (Figura 3b) mostra as áreas afetadas pela infiltração como áreas frias, pois indica a presença de água, que tem temperatura menor do que a parede e o teto, o que enfria as áreas atingidas. No entanto, é importante diferenciar o comportamento entre a parede e o teto. Este último é atingido pela radiação solar na parte superior e, portanto, apresenta maior temperatura do que a parede. Assim, observa-se uma diferença marcada em relação às áreas com e sem infiltração pelas diferenças de temperaturas próximas a $3,3{ }^{\circ} \mathrm{C}\left(\mathrm{SP} 2=32,9^{\circ} \mathrm{C}-\mathrm{SP} 1=29,6{ }^{\circ} \mathrm{C}\right)$. $\mathrm{Na}$ parede observam-se diferenças menores do que $2,3{ }^{\circ} \mathrm{C} \quad\left(\mathrm{SP} 4=29,5{ }^{\circ} \mathrm{C}-\mathrm{SP} 3=27,2{ }^{\circ} \mathrm{C}\right) . \quad \mathrm{A}$ termografia infravermelha, neste caso, permite distinguir a área afetada pela umidade e os possíveis focos da infiltração com vista à identificação do problema e reparos.

Figura 2 - Laje do edifício das salas do LIE

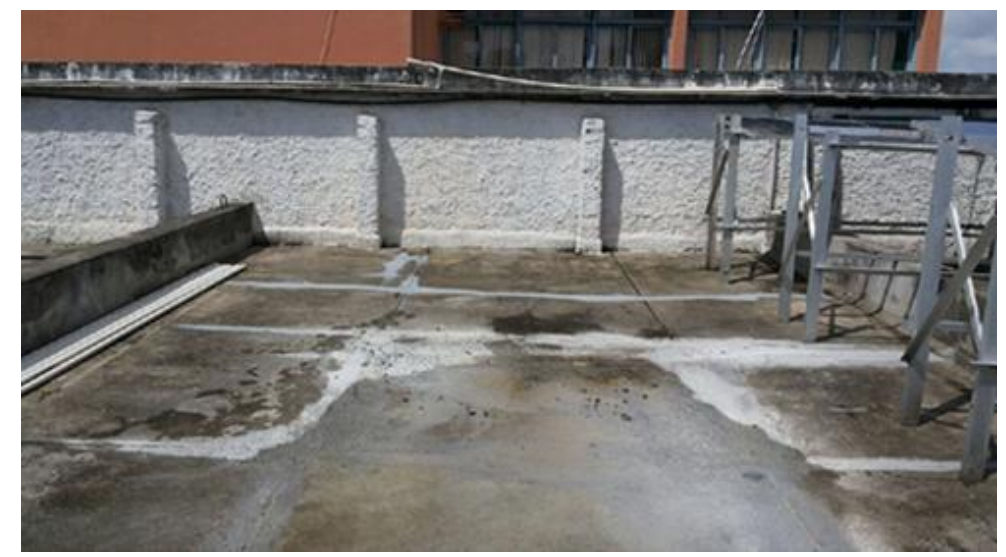

332 Rocha, J. H. A.; Santos, C. F. dos; Oliveira, J. B. de; Albuquerque, L. K. dos S.; Póvoas, Y. V. 
Figura 3 - Parede 1 e teto

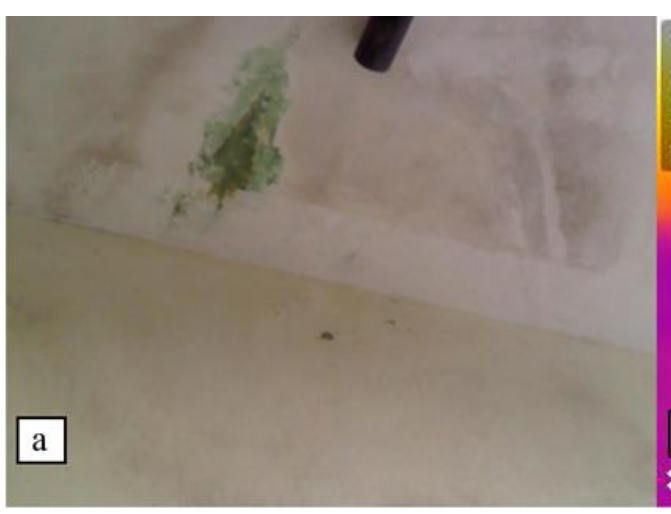

(a) Imagem digital

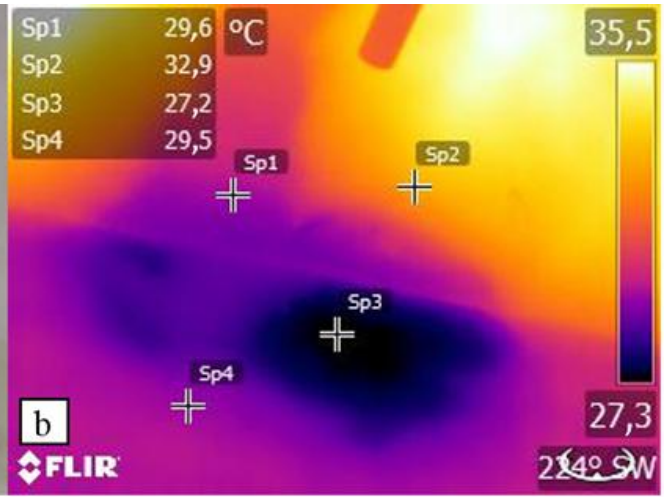

(b) Imagem térmica
Em outra área da mesma parede (Figura 4a), observa-se uma fissura que não apresenta sinais de infiltração ou umidade, mas na imagem térmica (Figura 4b) podem-se notar áreas com menor temperatura, o que indica infiltração em estágio inicial e com possível causa na fissura; no entanto, a diferença da temperatura da parede sem umidade e da área afetada pela infiltração é mínima, $0,6^{\circ} \mathrm{C}$ $\left(\mathrm{SP} 2=25,8^{\circ} \mathrm{C}-\mathrm{SP} 1=25,2^{\circ} \mathrm{C}\right)$.

$\mathrm{Na}$ parede 2 (Figura 5a), localizada na direção leste, pode-se detectar a presença de umidade quase imperceptível na inspeção visual. A causa da infiltração é atribuída principalmente a falhas no sistema de impermeabilização. Apesar de os sinais de infiltração serem discretos, consegue-se perceber uma infiltração generalizada na laje, no termograma da Figura 5b. A parede apresenta algumas áreas afetadas visualizadas como áreas frias. A diferença de temperatura entre essas áreas é de $1,2^{\circ} \mathrm{C}\left(\mathrm{SP} 3=28,1^{\circ} \mathrm{C}-\mathrm{SP} 1=26,9^{\circ} \mathrm{C}\right)$.

Foi possível analisar também o teto desse setor. Durante a inspeção visual não foi detectada nenhuma manifestação patológica, como pode ser visto na Figura 6a, mas durante o ensaio com a câmera termográfica foi percebida uma área fria (Figura 6b), o que revela a presença de umidade nesse setor, que ainda não atingiu a superfície do teto da sala e apresentou diferença de $2,5^{\circ} \mathrm{C}$ (SP2 - SP1).

A parede 3, localizada em direção sul, mostrada na Figura 7a, apresentou evidência mínima de umidade, sendo pouco visível na inspeção visual e sem delimitação clara da área afetada, porém tinha uma mancha na pintura do teto. $\mathrm{Na}$ imagem térmica (Figura 7b) observam-se as áreas afetadas pela infiltração de água com temperaturas baixas, mostrando maior área afetada na parede. No teto percebem-se áreas frias com diferença próxima a 2 ${ }^{\circ} \mathrm{C}$ (SP5 - SP4), e na parede, com diferença de 1,1 ${ }^{\circ} \mathrm{C}$ (SP2 - SP1). Pode-se notar que a variação de temperatura é maior no teto, pois é aquecido pelo sol na parte superior, o que cria maior contraste térmico, mas as paredes que estão sem contato solar direto pela superfície externa ou interna são apenas aquecidas e esfriadas pelo ambiente, pelo mecanismo de convecção.

A parede 4 e o teto mostrado na Figura $8 \mathrm{a}$, orientados a oeste, apresentavam uma clara mancha de umidade, proveniente da falha no sistema de impermeabilização devido à chuva acumulada na laje. A imagem térmica (Figura 8b) confirma a presença da umidade na mesma área observada visualmente, o que mostra que, neste caso, a infiltração não afeta outras áreas. É importante perceber que a superfície externa da parede analisada está com exposição solar durante a tarde, no momento do ensaio, portanto é aquecida na superfície exposta ao ambiente, transferindo esse calor para a superfície interna, mas sendo interrompida na área da infiltração devido à presença de água. Por isso, neste caso, a diferença apresenta-se maior do que nas outras paredes estudadas, mostrando valor de $5,8^{\circ} \mathrm{C}$ (SP3 - SP1), sendo as áreas afetadas claramente identificadas e definidas no termograma.

Pode-se notar que existem dois casos para a detecção de umidade nos tetos e paredes: o primeiro quando a superfície externa não tem contato solar direto (Figura 9a), e o segundo quando está exposta à radiação solar (Figura 9b). Observa-se que as diferenças de temperatura $(\Delta \mathrm{T})$ entre as áreas sem umidade e as afetadas pela infiltração apresentam valores mais altos no segundo caso do que no primeiro, isto porque, quando a radiação solar atinge a superfície externa, uma parte é refletida e outra absorvida. A radiação absorvida é transferida através do objeto (teto ou parede), aquecendo-o e, portanto, emitindo maior radiação do que sem presença solar. A área afetada pela umidade apresenta menor temperatura devido à presença da água e, portanto, emite menor radiação. 
Figura 4 - Parede com fissura

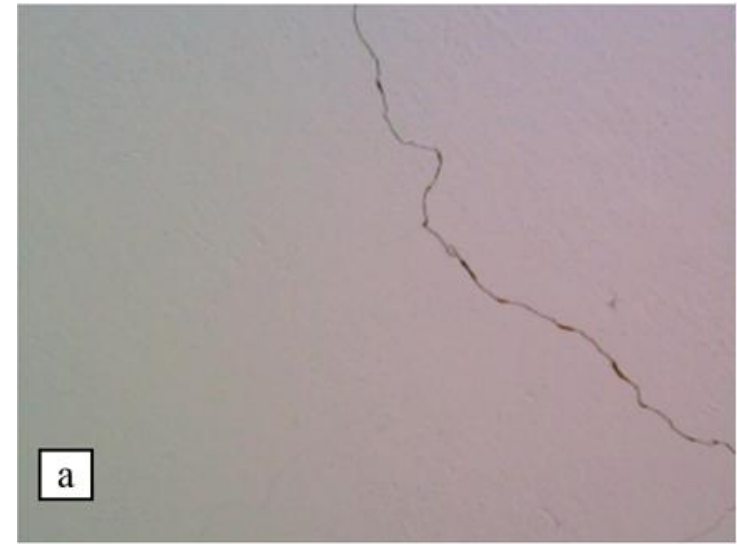

(a) Imagem digital

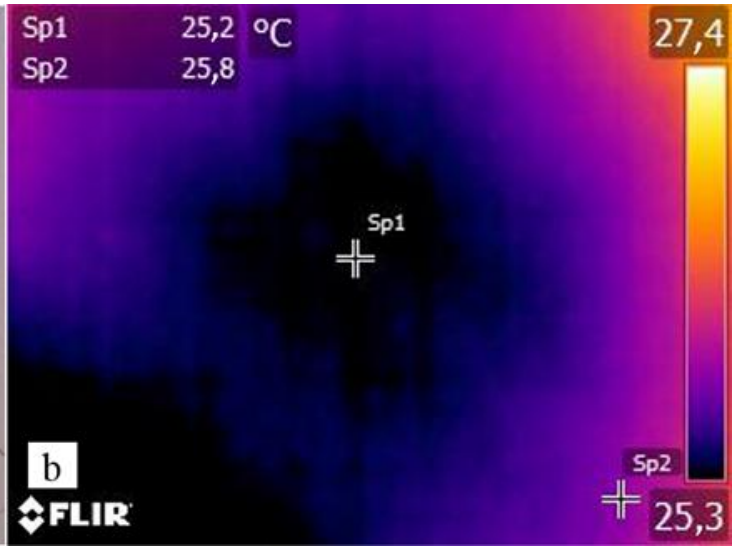

(b) Imagem térmica

Figura 5 - Parede 2 e teto

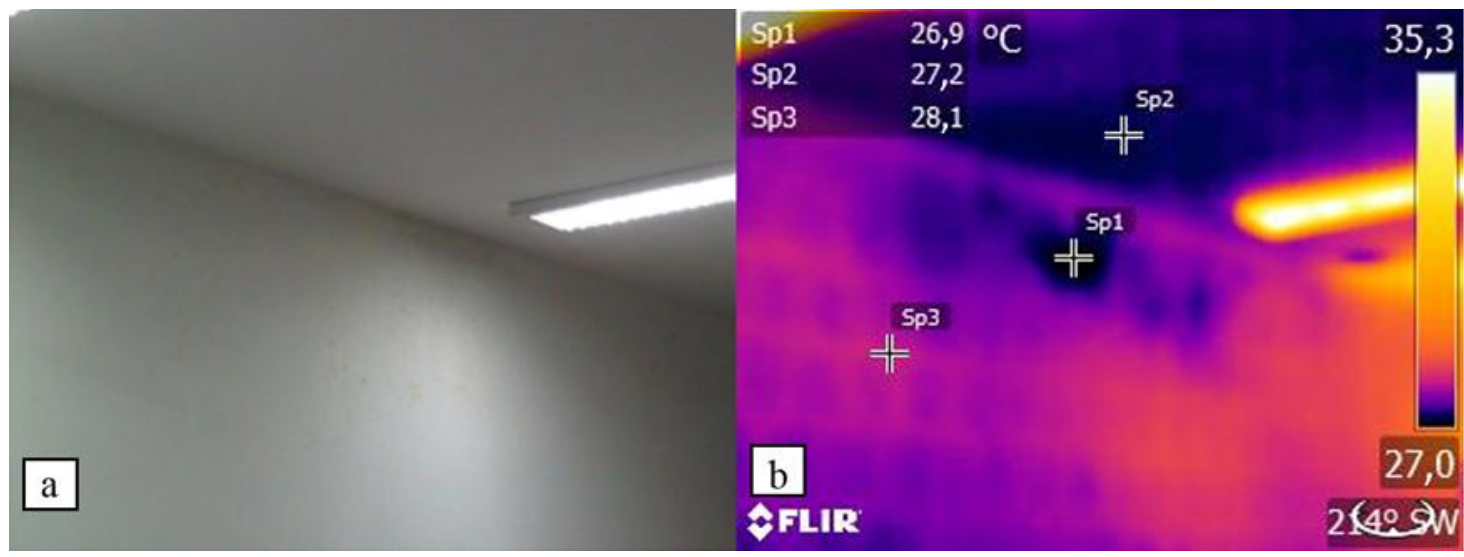

(a) Imagem digital

(b) Imagem térmica

Figura 6 - Teto do LIE

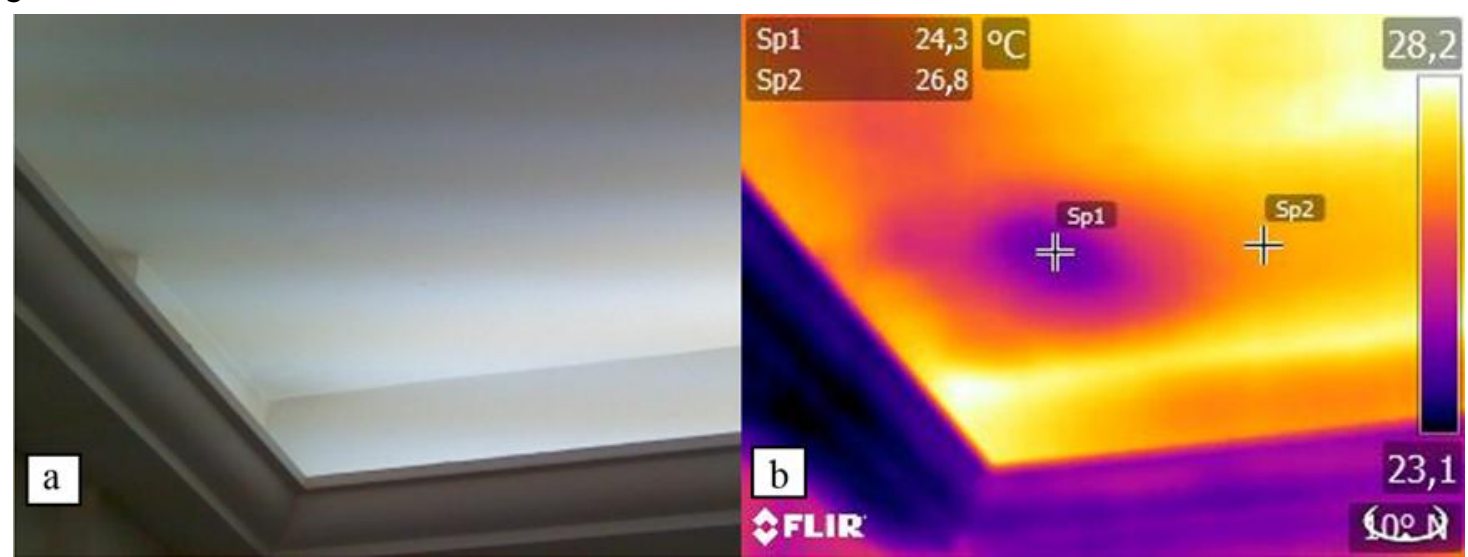

(a) Imagem digital

(b) imagem térmica

334 Rocha, J. H. A.; Santos, C. F. dos; Oliveira, J. B. de; Albuquerque, L. K. dos S.; Póvoas, Y. V. 
Figura 7 - Parede 3 e teto

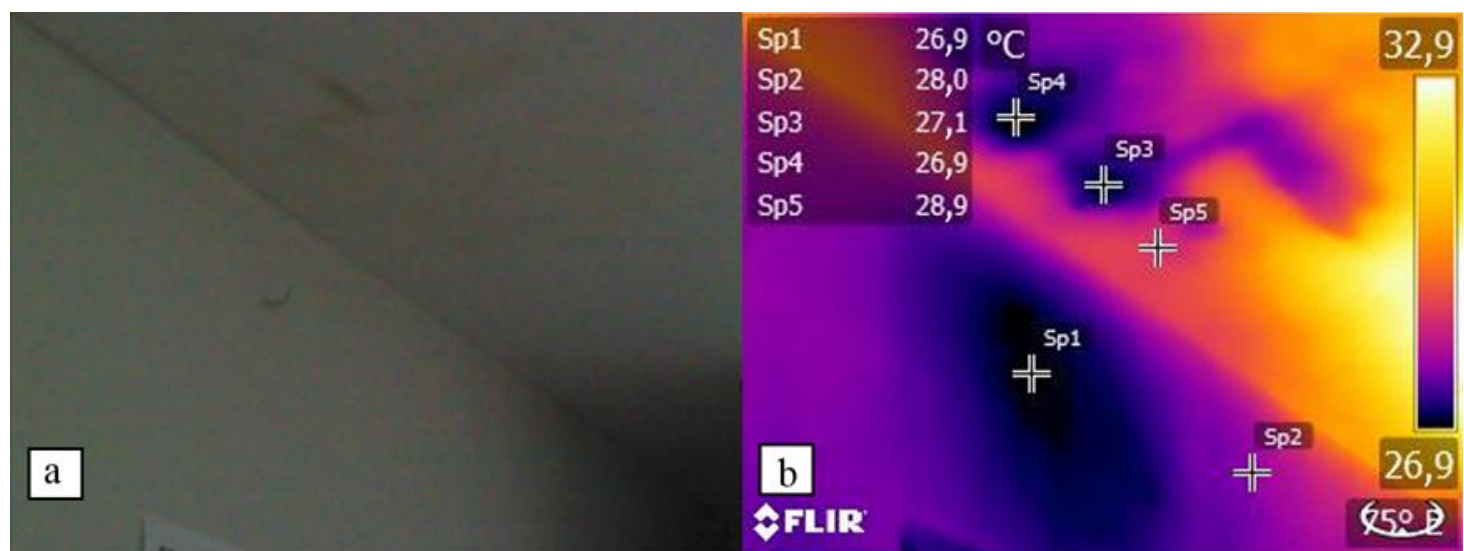

(a) Imagem digital

(b) Imagem térmica

Figura 8 - Parede 4 e teto

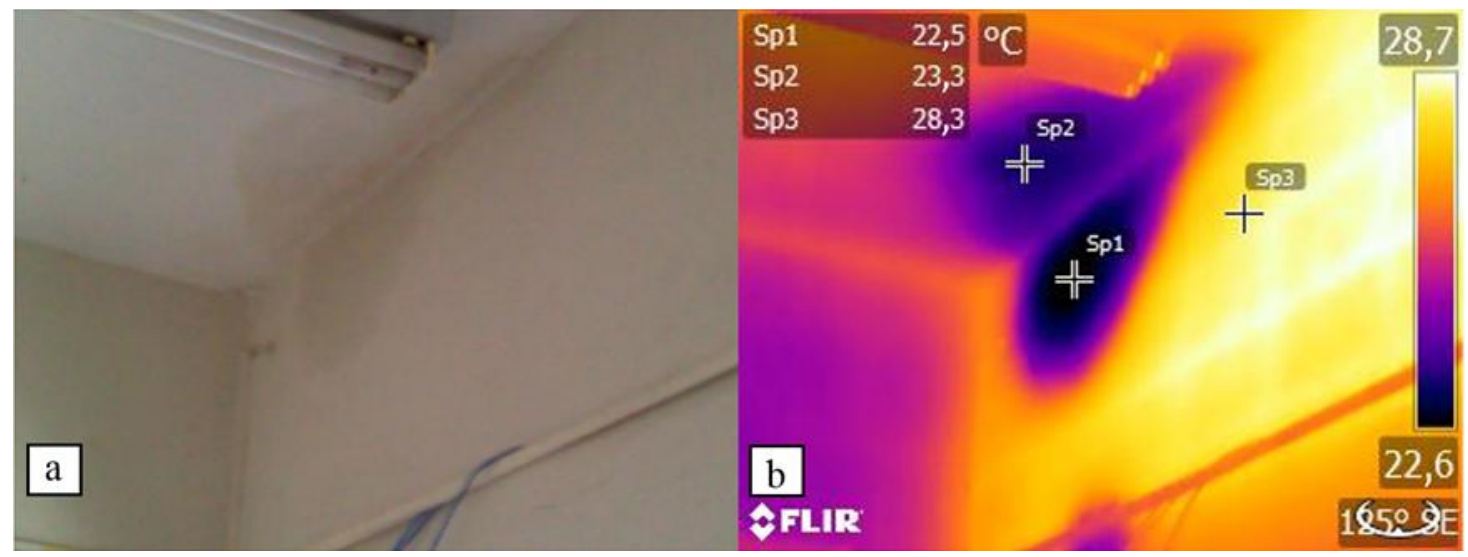

(a) Imagem digital

(b) Imagem térmica

Figura 9 - Detecção de umidade em parede e tetos

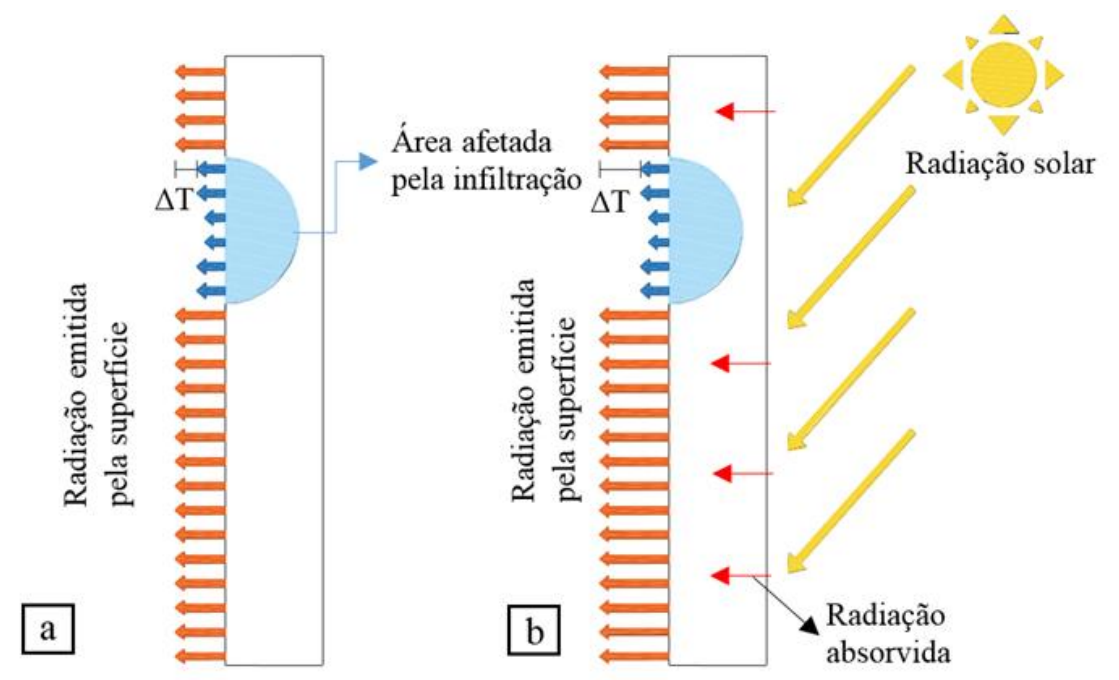

(a) Sem contato solar (b) Com contato solar na superfície externa 
Os resultados são comparáveis com os obtidos por outros autores (BARREIRA; ALMEIDA; DELGADO, 2016; MELRINHO; MATIAS; FARIA, 2015; LERMA; CABRELLES; PORTALÉS, 2011), que concluem que a termografia infravermelha tem o potencial de detectar umidade como áreas de menor temperatura, apesar de que nesses estudos a aplicação foi feita através da influência do sol e de outras fontes externas. Já Melrinho, Matias e Faria (2015) estabelecem que essas áreas apresentam menores temperaturas devido à inércia térmica da água, que é elevada, o que permite absorver maior quantidade de energia térmica sem alteração significativa do estado termodinâmico. É por isso que essas zonas apresentam diferentes temperaturas mesmo que a parede esteja ou não exposta ao sol ou a outras fontes.

\section{Laboratório Avançado de Construção Civil (LACC)}

A área em estudo apresentava manifestações patológicas provenientes de infiltrações causadas pela água da chuva que respingava do telhado da construção vizinha, que é mais baixo que o telhado do laboratório. A parede externa, localizada em direção leste, apresentava áreas com bolor e desagregação da pintura, como é visto na Figura 10 .

A parede em estudo, tanto na área externa quanto na interna, apresentava manifestação patológica característica de infiltração. Através das imagens termográficas foi possível identificar na área interna onde a umidade se concentrava.

A área interna da parede 5 (Figura 11a) apresentava manchas características de umidade, que também podiam ser vistas na imagem térmica (Figura 11b). A área afetada pela infiltração é apresentada como área fria em relação àquela sem problema e se apresenta com diferenças de $1,2{ }^{\circ} \mathrm{C}$ (SP2-SP1).

Figura 10 - Parede externa do LACC

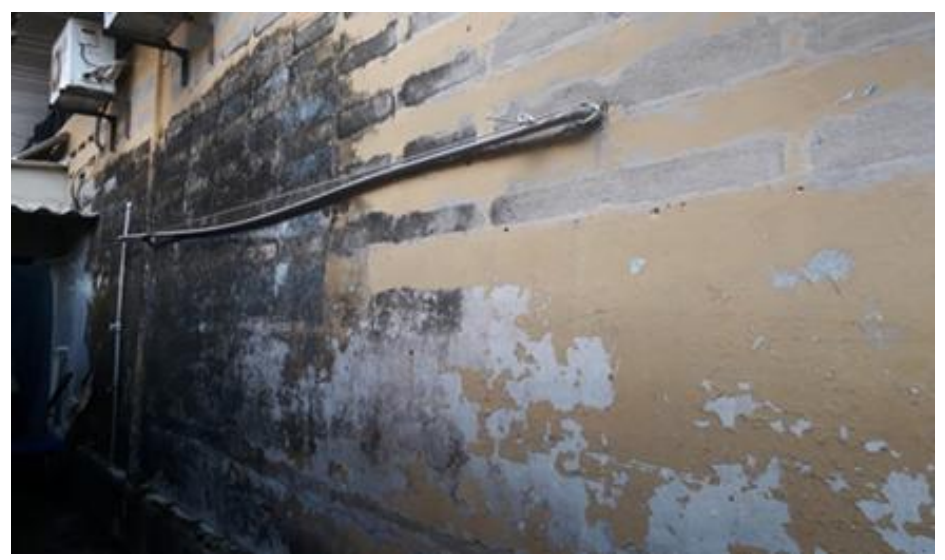

Figura 11 - Parede 5

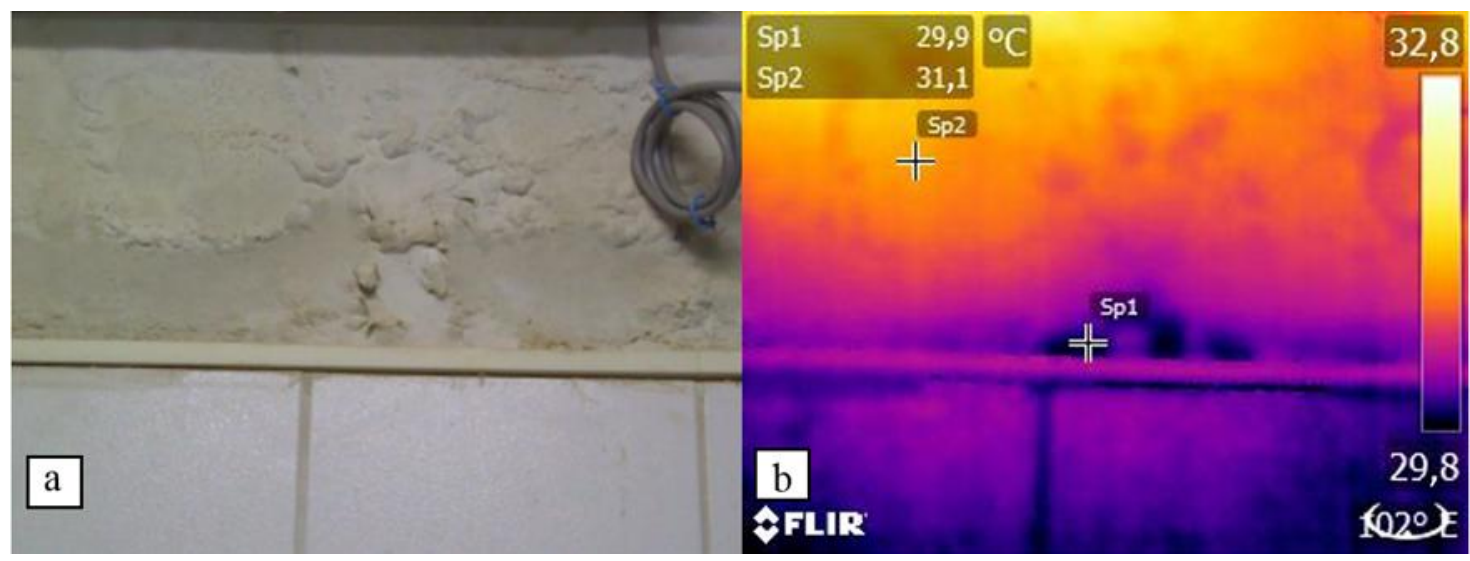

(a) Imagem digital

(b) Imagem térmica

336 Rocha, J. H. A.; Santos, C. F. dos; Oliveira, J. B. de; Albuquerque, L. K. dos S.; Póvoas, Y. V. 
A Figura 12a mostra uma área próxima à pia do laboratório constituída de revestimento cerâmico, em que, mediante uma simples inspeção visual, não é detectado indício de infiltração. Porém, a imagem térmica (Figura 12b) permite observar toda a área afetada pela infiltração proveniente da parede externa. Nesse caso, a diferença estava limitada a valores de $0,6{ }^{\circ} \mathrm{C}(\mathrm{SP} 2-\mathrm{SP} 3)$ e $0,4{ }^{\circ} \mathrm{C}$ (SP2 - SP1). Isso pode ser devido ao fato de a superfície externa da parede estar localizada em uma região que não recebe radiação solar em nenhuma hora do dia, sendo apenas aquecida pela temperatura ambiente, de forma a desenvolver pequenas diferenças. Outro fator importante é a presença de revestimento cerâmico, que pode impedir que a radiação emitida pela parede seja captada de forma direta pela câmera. A radiação emitida pela superfície da parede é transferida para a placa, o que afeta a temperatura desta. A câmera capta a radiação emitida pela placa e, consequentemente, os diferenciais de temperatura, que, neste caso, são menores se comparados com uma parede sem revestimento cerâmico (Figura 13).

\section{Figura 12 - Lavado do LACC}

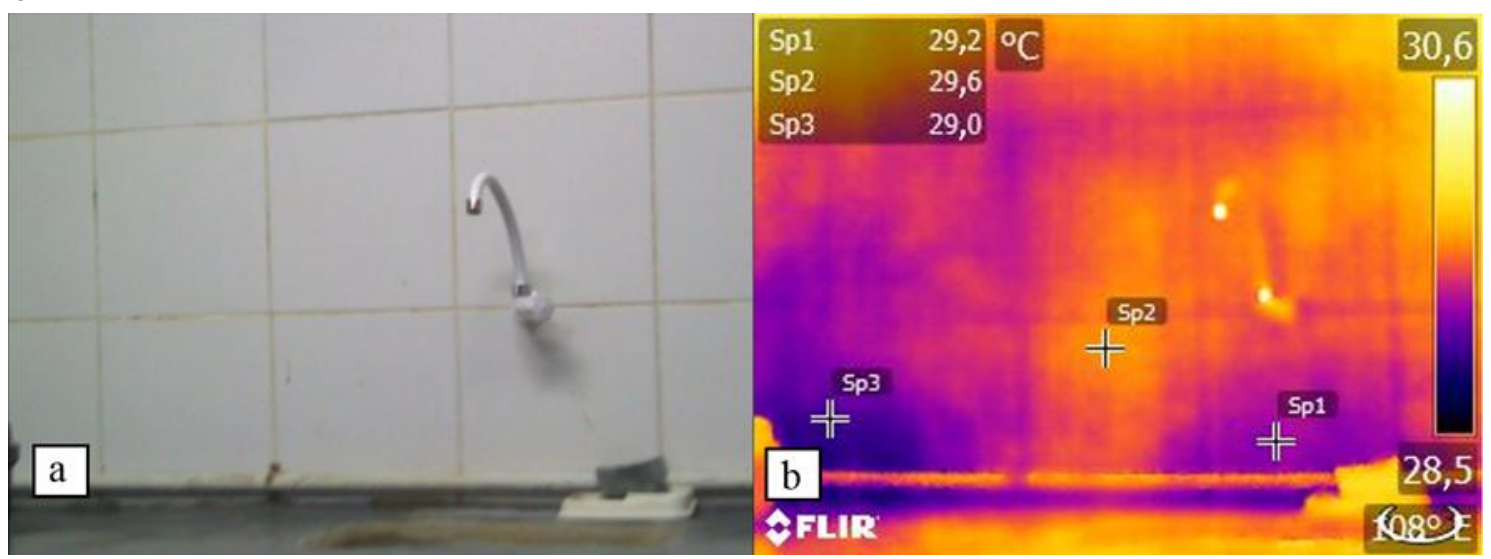

(a) Imagem digital

(b) Imagem térmica

Figura 13 - Radiação emitida pela superfície com revestimento cerâmico

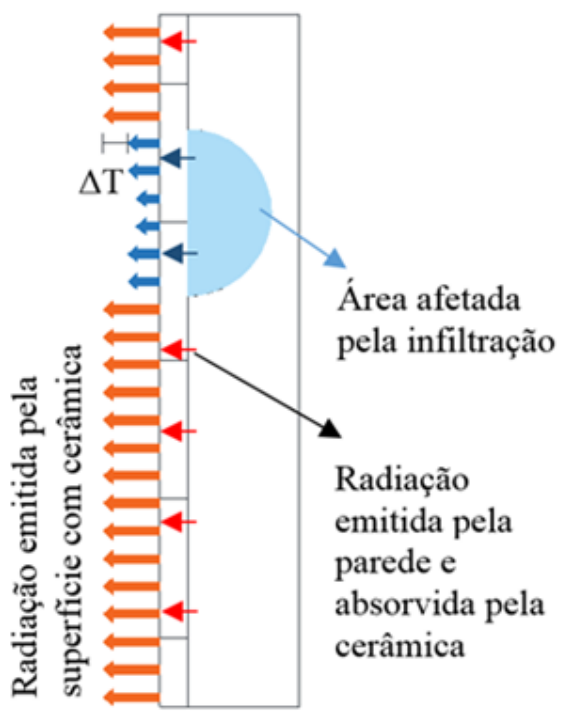


Lourenço, Matias e Faria (2017) também demonstraram que é possível detectar umidade em paredes com revestimento cerâmico com termografia infravermelha, considerando adicionalmente que a água diminui a temperatura do revestimento através do processo de evaporação, e que o comportamento da temperatura superficial é parecido quando apenas estiver a parede sem isolamento; no entanto, como foi descrito, é mais difícil o desenvolvimento de diferenciais térmicos. Entre outros resultados de detecção de umidade situam-se os obtidos por Melrinho, Matias e Faria (2015) e Edis, FloresColen e Brito (2014). Estes últimos, de forma complementar, indicam que, quanto maior for a diferença de conteúdo de umidade entre as áreas úmidas e secas, maior será a variação de temperatura.

Apesar de alguns autores indicarem que diferenças maiores que $1{ }^{\circ} \mathrm{C}$ revelam defeitos (MALDAGUE, 2001), no presente estudo foi demonstrado que mesmo diferenças menores que $1{ }^{\circ} \mathrm{C}$ são um bom indicativo para a detecção de anomalias em áreas internas, pois não existe a possibilidade de falsas detecções, como no caso de áreas externas quando expostas ao sol, onde a radiação solar pode intervir na visualização de "ruídos" nos termogramas. No entanto, quanto maior essa diferença, mais nítidos serão os contrastes térmicos produzidos nos termogramas.

A infiltração normalmente é detectada como uma área fria porque a água que ingressa na estrutura tem temperatura mais baixa, o que esfria as áreas atingidas e modifica a inércia térmica do material (MELRINHO; MATIAS; FARIA, 2015). Entretanto, também pode ocorrer o comportamento inverso, a depender das características das infiltrações; assim, estas devem ser consideradas para evitar o fornecimento de diagnósticos incorretos.

A termografia infravermelha consiste na medição da radiação emitida pela superfície de um objeto (BARREIRA; ALMEIDA; DELGADO, 2016). A existência de outros objetos que impeçam a medição direta tem influência nos resultados, o que pode ser uma limitação para a detecção de problemas ocultos como a infiltração. Não obstante, a captação de uma diferença de temperatura visível no termograma é um bom indicativo de problemas internos, neste caso, umidade.

Durante o ensaio a distância entre a câmera termográfica e a superfície inspecionada não mostrou influência nos resultados, pois não foram encontradas diferenças significativas. Contudo, embora a distância afete a clareza e a nitidez das imagens térmicas (VENKATARAMAN; RAJ 2003), a câmera utilizada possui boa resolução e sensibilidade térmica, o que permite resultados confiáveis.

\section{Conclusões}

A termografia infravermelha se mostrou um ensaio adequado para a detecção de infiltração e de problemas relacionados, os quais foram detectados durante todo o tempo do ensaio, por fornecer mais informações que uma inspeção visual. Embora possam ser obtidas informações como localização e área da umidade, elas são apenas qualitativas, uma vez que as diferenças térmicas entre as áreas intactas e afetadas não indicam a profundidade ou a gravidade do problema.

O ensaio pode ser limitado na presença de outros objetos que não permitam a radiação direta da superfície inspecionada porque reduzem os valores dos contrastes térmicos e a precisão da detecção.

As condições ambientais têm influência indireta na detecção quando da observação de áreas internas, principalmente aquelas que têm contato solar em sua superfície externa, ao criar maior diferença térmica interna. No entanto, a infiltração pode ser detectada em áreas onde apenas ocorra o mecanismo de convecção, como foi visto na maior parte dos ensaios.

Os resultados obtidos permitem mostrar a potencialidade da aplicação passiva do ensaio da termografia infravermelha na inspeção de infiltrações em áreas internas de edificações onde existem condições diferentes das áreas externas que apresentam maior influência das condições ambientais, pois a infiltração de água influi na temperatura dos elementos e cria, dessa maneira, diferenciais térmicos, que, apesar de serem pequenos, podem ser detectados pelas câmaras termográficas. A informação obtida pode ser usada para realizar reparos, em vez de aguardar a necessidade de fazer intervenções custosas.

\section{Referências}

AGGELIS, D. et al. Combined Use of Thermography and Ultrasound For the Characterization of Subsurface Cracks in Concrete. Construction and Building Materials, v. 24, n. 10, p. 1888-1897, 2010.

ASSOCIAÇÃO BRASILEIRA DE NORMAS TÉCNICAS. NBR 15572: ensaios não destrutivos: termografia por infravermelho: guia para inspeção de equipamentos elétricos e mecânico. Rio de Janeiro, 2013. 
BAGAVATHIAPPAN, S. et al. Infrared Thermography For Condition Monitoring: a review. Infrared Physics \& Technology, v. 60, n. 1, p. 35-55, 2013.

BARREIRA, E.; ALMEIDA, R. M. S. F.; DELGADO, J. M. P. Q. Infrared Thermography For Assessing Moisture Related Phenomena in Building Components. Construction and Building Materials, v. 110, p. 251-269, 2016.

BARREIRA, E.; ALMEIDA, R.; MOREIRA, M. An Infrared Thermography Passive Approach to Assess the Effect of Leakage Point in Buildings. Energy and Buildings, v. 140, p. 224-235, 2017.

BARREIRA, E.; FREITAS, V. P. de. Evaluation of Building Materials Using Infrared Thermography. Construction and Building Materials, v. 21, n. 1, p. 218-224, 2007.

BERNHOEFT, L. F.; MELHADO, S. B. A Importância dos Sistemas de Impermeabilização na Durabilidade das Estruturas. In: CONGRESO IBEROAMERICANO, 1.; JORNADA "TÉCNICAS DE RESTAURACIÓN Y CONSERVACIÓN DEL PATRIMONIO”, 8., La Plata, 2009. Anais... Buenos Aires, 2009.

EDIS, E.; FLORES-COLEN, I.; BRITO, J. Passive Thermographic Detection of Moisture Problems in Façades With Adhered Ceramic

Cladding.Construction and Building Materials, v. 51, p. 187-197, 2014.

FLIR. User's Manual FLIR Txx Series. Wilsonville: FLIR, 2014.

FOX, M.; GOODHEW, S.; WILDE, P. Building Defect Detection: external versus internal thermography. Building and Environment, v. 105, p. 317-331, 2016.

FREITAS, J.; CASAREK, H.; CASCUDO, O. Utilização de Termografia Infravermelha Para Avaliação de Fissuras em Fachadas Com Revestimento de Argamassa e Pintura. Ambiente Construído, Porto Alegre, v. 14, n. 1, p. 57-73, jan./mar. 2014.

GOOGLE. Google Earth. Version 9. 2017.

Recife, Brasil. Disponível em:

<https://earth.google.com/web/>. Acessoem: 25 set. 2017.

GUCUNSKI, N. et al. Non-Destructive Testing to Identify Bridge Deck Deterioration. $2^{\text {nd }}$. ed. Washington: SRHP, 2013.

HUDA, A. S.; TAIB, S. Application of Infrared Thermography For Predictive/Preventive Maintenance of Thermal Defect in Electrical Equipment. Applied Thermal Engineering, v. 61, n. 2, p. 220-227, 2013.
JIMENO, C. L. Guía de la Termografia:

aplicaciones en ahorro y eficiencia energética. Madrid: IDEA, 2011.

JONOV, C. M. P.; NASCIMENTO, N. de O.; PAULA E SILVA, A. de. Avaliação de Danos às Edificações Causados Por Inundações e Obtenção dos Custos de Recuperação. Ambiente

Construído, Porto Alegre, v. 13, n. 3, p. 75-94, jul./set. 2013.

KUTIN, M.; ADAMOVIE, Z. Tensile Features of Welded Joint Testing by Thermography. Russian Journal of Nondestructive Testing, v. 46, p. 386-393, 2010.

LERMA, J. L.; CABRELLES, M.; PORTALÉS, C. Multitemporal Thermal Analysis to Detect Moisture on a Building Façade. Construction and Building Materials, v. 25, n. 5, p. 2190-2197, 2011.

LIZAK, F.; KOLCUN, M. Improving Reliability and Decreasing Losses of Electrical System With Infrared Thermography.

ActaElectrotechnicaetInformatica, v. 8, p. 6063, 2008.

LOURENÇO, T.; MATIAS, L.; FARIA, P. Anomalies Detection in Adhesive Wall Tiling Systems by Infrared Thermography. Construction and Building Materials, v. 148, p. 419-428, 2017.

MALDAGUE, X. Infrared and Thermal

Testing: nondestructive testing handbook. 3. ed. Columbus, OH: Patrick O. Moore, 2001.

MELRINHO, A.; MATIAS, L.; FARIA, P. Detecção de Anomalias em Impermeabilizações de Coberturas em Terraço Através da Termografia de Infravermelhos. Tech ITT, v. 13, n. 37, p. 29-38, 2015.

O'GRADY, M.; LECHOWSKA, A.; HARTE, A. Infrared Thermography Technique as in-situ Method of Assessing Heat Loss Through Thermal Bridging. Energy and Buildings, v. 135, p. 20-32, 2017.

$\mathrm{OH}, \mathrm{T}$. et al. Comparison of NDT Methods For Assessment of a Concrete Bridge Deck. Journal of Engineering Mechanics, v. 193, n. 3, p. 305314, 2013.

OLIVEIRA, G. F. P. de. Potencialidades da Termografia Para o Diagnóstico de Patologias Associadas à Humidade. Porto, 2013. 194 f. Dissertação (Mestrado em Engenharia Civil) Faculdade de Engenharia, Universidade do Porto, Porto, 2013.

OTHMAN, N. L. et al.A Case Study on Moisture Problems and Building Defects. Procedia-Social and Behavioral Sciences, v. 170, p. 27-36, 2015. 
REHMAN, S. et al. Nondestructive Test Methods For Concrete Bridges: a review. Construction and Building Materials, v. 107, n. 15, p. 58-86, 2016.

\section{RIGHI, G. V. Estudos dos Sistemas de}

Impermeabilização: patologias, prevenções e correções: análise de casos. Santa Maria, 2009. 95 f. Dissertação (Mestrado em Engenharia Civil) Universidade Federal de Santa Maria, Santa Maria, 2009.
SILVA, D. D. S. da. Diagnóstico de Patologias em Fachadas Utilizando Termografia. Porto, 2012. 132 f. Dissertação (Mestrado em Engenharia Civil) - Faculdade de Engenharia, Universidade do Porto, Porto, 2012.

VENKATARAMAN, B.; RAJ, B. Performance Parameters For Thermal Imaging Systems.

Insight, v. 45, p. 531-353, 2003.

ZHAO, H. et al. Application of Lock-in Thermography For the Inspection of Disbonds in Titanium Alloy Honeycomb Sandwich Structure. Infrared Physics \& Technology, v. 81, p. 69-78, 2017.

\author{
Joaquin Humberto Aquino Rocha \\ Departamento de Engenharia Civil | Escola Politécnica de Pernambuco | Rua Benfica, 455, Madalena | Recife - PE - Brasil | CEP 50720 - \\ 001 | Tel.: (81) 9912-2394 | E-mail: jhar_pec@poli.br \\ Cynthia Firmino dos Santos \\ Departamento de Engenharia Civil | Escola Politécnica de Pernambuco | Tel.: (81) 8679-4513 | E-mail: cfs_pec@poli.br \\ Jaquelline Barros de Oliveira \\ Departamento de Engenharia Civil | Escola Politécnica de Pernambuco | Tel.: (81) 8741-3838 | E-mail: jaquebarros20@gmail.com \\ Larissa Kelly dos Santos Albuquerque \\ Departamento de Engenharia Civi | Escola Politécnica de Pernambuco | Tel.: (81) 9734-2119 | E-mail: I_k_albuquerque@hotmail.com \\ Yêda Vieira Póvoas \\ Departamento de Engenharia Civil | Escola Politécnica de Pernambuco | Tel.: (81) 9976-0859 | E-mail: yeda.povoas@gmail.com
}

Revista Ambiente Construído

Associação Nacional de Tecnologia do Ambiente Construído

Av. Osvaldo Aranha, $99-3^{\circ}$ andar, Centro

Porto Alegre - RS - Brasil

CEP $90035-190$

Telefone: +55 (51) 3308-4084

Fax: +55 (51) 3308-4054

www.seer.ufrgs.br/ambienteconstruido

E-mail: ambienteconstruido@ufrgs.br

(c) ()

340 Rocha, J. H. A.; Santos, C. F. dos; Oliveira, J. B. de; Albuquerque, L. K. dos S.; Póvoas, Y. V. 